\title{
VERFLIXT VERNETZT
}

Liebe Leserin, lieber Leser,

das Connected Car wird Wirklichkeit. Zwar nicht von heute auf morgen, aber doch unaufhaltsam. In den kommenden Jahren werden Auto und Fahrer sich immer aktiver und umfassender mit anderen Verkehrsteilnehmern, dem Internet und der Umwelt vernetzen. Car-to-X-Kommunikation wird alltäglich.

Das Szenario ist vielschichtig: Smartphones, Consumer Electronics und die Cloud suchen ihren Weg ins Auto, wodurch sich die E/E-Architektur des Automobils rasant und bisweilen auch radikal verändert. Neue Telematik- und Entertainment-Anwendungen fassen Fuß. Fahrerassistenzsysteme werden komplexer, und die Themen Energieund Reichweitenmanagement stehen auf der automobilen Tagesordnung weit oben.

Hinzu kommen die Erwartungen vieler Kunden, die sich ein modernes, leicht $\mathrm{zu}$ bedienendes Auto wünschen, das vollständig und clever ins „Netz der Dinge“ eingebunden ist. Und last but not least sind da die Zwänge von Herstellern, Zulieferern und Firmen aus der Informations- und Kommunikationstechnologie: Car-to-X ist ein Muss, um zu beweisen, dass das eigene Unternehmen tatsächlich Innovations- und Technologieführer ist und bleiben wird.

Gerade die Herausforderungen an OEMs und Zulieferer sind enorm, denn die Komplexität der Themen macht die Entscheidung, auf welche technologischen und strategischen Pferde ein Unternehmen setzen sollte, durchaus heikel. Die Aufgabenstellung erscheint übergroß: Wie können Firmen modernste, sichere Car-to-X-Anwendungen so schnell wie möglich in den Markt bekommen, zu möglichst geringen Kosten und einer vielversprechenden Profit-Erwartung, bei hoher technischer Flexibilität und ausgeprägter Zukunftssicherheit? Wie harmonisiert man die sehr unterschiedlichen Entwicklungszyklen beispielsweise der Automobil- und der Informationstechnologie?

Diese und andere drängenden Fragen lassen sich nicht im Schnellverfahren beantworten, sie sind nur Schritt für Schritt lösbar, mit Mut, Cleverness und Weitsicht. Aktuelle Antworten und Ansätze, Denkanstöße, Ideen und Innovationen stellen die Autoren dieser ATZagenda vor. Wir wünschen eine inspirierende Lektüre, und wir freuen uns auf ein Feedback von Ihnen. Schreiben Sie uns Ihre Meinung!

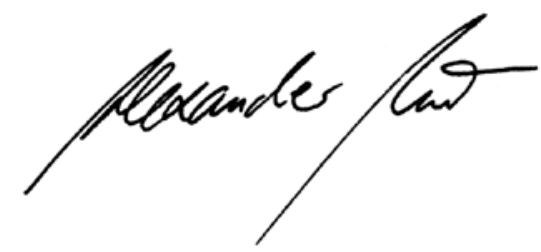

DR. ALEXANDER HEINTZEL, Chefredakteur Wiesbaden, 10. Oktober 2013

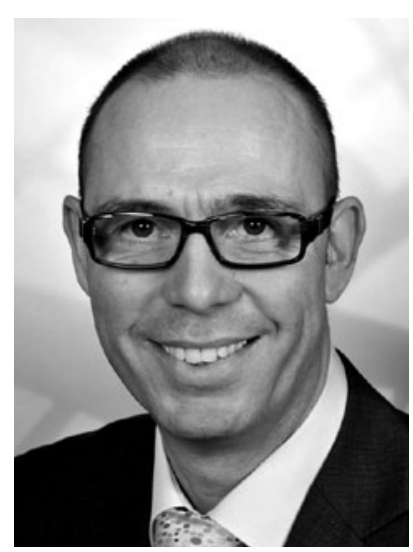

